\title{
Genetic characterisation of staphylococci of food-producing animals in Senegal. PVL detection among MSSA
}

\author{
Olouwafemi Mistourath Mama', Modou Dieng², Bocar Hanne³, Laura Ruiz-Ripa', Codou Gueye Mar Diop² and \\ Carmen Torres $^{1 *}$ (D)
}

\begin{abstract}
Background: Food-producing animals can be a vehicle for staphylococcal species as well as their virulence and antimicrobial resistance genes. This work aimed to analyse the diversity of staphylococcal species in food-producing animals in Dakar/Senegal, and to determine the antimicrobial resistance phenotype/genotype and virulence factors of recovered isolates. Nasal samples of 149 cows and 199 chickens (348 animals) were collected from one slaughterhouse and a local market respectively, and were inoculated on selective media for staphylococci recovery. For S. aureus isolates, molecular typing (spa-type, MLST) was performed by PCR/sequencing, and the presence of 27 virulence genes (exfoliative and toxic shock toxins, PVL, haemolysins and enterotoxins) as well as the gene scn were analysed by PCR. Susceptibility to twelve antibiotics was studied by disc-diffusion method for all staphylococci; the resistance genes involved were screened by PCR.
\end{abstract}

Results: Staphylococcus spp. was present in 3 and $26.8 \%$ of chicken and cow nasal samples, respectively. Seven S. aureus isolates and forty isolates of other staphylococcal species were identified. S. aureus isolates were recovered from cow $(n=6)$ and chicken $(n=1)$ samples, belonging to four genetic lineages: t084/ST15 $(n=1)$; t10579/ST291 $(n=3) ; \mathrm{t} 355, \mathrm{t} 4690 / \mathrm{ST} 152(n=2) ;$ and t6618/ST6 $(n=1)$. All S. aureus were methicillin-susceptible, penicillin-resistant (blaZ), and two of them were also tetracycline-resistant $[\operatorname{tet}(\mathrm{K})]$. All the isolates carried at least one of the virulence genes tested. The PVL genes were detected in three ST15 and ST152 isolates. They all harboured haemolysins encoding genes and lacked the scn gene. The other staphylococci recovered were S. sciuri $(n=16)$, S. simulans $(n=$ $11)$, S. hyicus $(n=5)$, S. haemolyticus $(n=4)$, S. chromogenes $(n=3)$, and S. hominis $(n=1)$; they were all methicillinsusceptible and $27.5 \%$ tetracycline-resistant [tet $(\mathrm{K})$ and tet $(\mathrm{L})]$.

Conclusions: A low prevalence of $\mathrm{S}$. aureus was detected among food-producing animals, all susceptible to methicillin. However, the presence of virulence genes (lukF/lukS-PV, eta, tst, sea and see) is worrisome to the extent that they could be transferred to derived food and therefore, to humans.

\section{Background}

Staphylococcus species are common colonizers of skin and mucous membranes of humans and different animal species, but can become opportunistic pathogens causing skin and soft tissues infections (SSTIs) and mastitis, among others [1]. Furthermore, they are current contaminants of animal-derived food, being responsible for food intoxication [2]. S. aureus in particularly can

\footnotetext{
*Correspondence: carmen.torres@unirioja.es

'Departamento Agricultura y Alimentación, Área de Bioquímica y Biología Molecular, Universidad de La Rioja, Madre de Dios 51, 26006 Logroño, Spain Full list of author information is available at the end of the article
}

express a large variety of pathogenicity factors, such as the staphylococcal enterotoxins, toxic shock syndrome toxin (TSST-1), and Panton-Valentine leucocidin (PVL), among others [3]. In fact, PVL is the most important toxin produced by $S$. aureus; it destroys membranes of host defence cells and erythrocytes by the synergetic action of two specific proteins named LukS-PV and LukF-PV [4]. PVL is though involved in severe skin infections, haemolysis, leucocyte destruction and necrosis [4] . PVL-positive methicillin susceptible S. aureus (MSSA) is considered endemic in the African continent [5]. The toxin has been detected worldwide in MSSA

(c) The Author(s). 2019 Open Access This article is distributed under the terms of the Creative Commons Attribution 4.0 International License (http://creativecommons.org/licenses/by/4.0/), which permits unrestricted use, distribution, and reproduction in any medium, provided you give appropriate credit to the original author(s) and the source, provide a link to the Creative Commons license, and indicate if changes were made. The Creative Commons Public Domain Dedication waiver (http://creativecommons.org/publicdomain/zero/1.0/) applies to the data made available in this article, unless otherwise stated. 
and methicillin resistant $S$. aureus (MRSA) isolates of diverse ecosystems, including humans (clinical or community-associated isolates) [6], wildlife [7], farm animals and animal-derived food [8]. The presence of the toxin in such different environments and in MRSA is a concern for public health and food safety, mainly for African regions, especially in those areas in which access to healthcare is limited. Moreover, S. aureus strains adapted to humans carry an innate immune evasion cluster (IEC) system that protects them against the human immune system [9]. The IEC consists of several genes, the combination of which gives a determined IEC type. The gene $s c n$, since present in all the IEC types, is considered to be a marker-gene for the detection of the IEC [9]. The presence of this system in a S. aureus isolate would suggest a human origin.

In general, studies about molecular epidemiology of staphylococci in African countries are being mainly performed in hospital environments $[10,11]$ and in the food sector [12], but there is scarce data related to farm animals [8]. Furthermore, those studies essentially focus on $S$. aureus species and most of them are performed in the Northern, Central and Southern regions of Africa [8]; consequently, data from West Africa is scarce, especially regarding Senegal. In Senegal, a study was carried out in 2012 on S. aureus from pigs and pig farmers, which highlighted the predominance of the clonal complexes $\mathrm{CC} 152$ and $\mathrm{CC} 15$, the low rate of resistance to methicillin and the frequent detection of PVL toxin [13], and a few years ago a review revealed that CC398, an emergent Livestock-associated $S$. aureus lineage in Europe [2, 14-17], was almost absent in animals and food in Africa [8]. In the said context, this study attempts to provide new information on molecular diversity, antimicrobial resistance and virulence determinants for $S$. aureus and other staphylococcal species in other food-producing animals (such as cow and chicken,) in Senegal (West Africa), and proposes an analysis of the potential occurrence of the lineage CC398 in the area.

\section{Results}

Staphylococcus species detection

Staphylococcus spp. were present in 3 and $26.8 \%$ of chicken and cow nasal samples, respectively. S. aureus was detected in seven of the tested animals (six cows and one chicken) (Table 1), whereas other staphylococcal species were found in cows ( $n=35$ isolates) and chickens ( $n=5$ isolates) (Table 2). One Staphylococcus isolate was obtained from all positive samples, except for one cow sample with two isolates (S. aureus and S. hyicus). A total of 47 staphylococci were recovered: S. aureus $(n=7), S$. sciuri $(n=16), S$. simulans $(n=11), S$. hyicus $(n=5), S$. haemolyticus $(n=4), S$. chromogenes $(n=3)$, and S. hominis $(\mathrm{n}=1)$.

\section{Staphylococcus aureus isolates: antimicrobial resistance, molecular typing and virulence}

All seven $S$. aureus isolates were susceptible to cefoxitin and were therefore considered as MSSA. The six isolates of cow origin showed resistance for penicillin (with blaZ gene) and two of them also to tetracycline (with tet $(\mathrm{K})$ gene). The $S$. aureus isolate of chicken origin showed susceptibility to all antimicrobials tested.

Five spa-types were detected among the $S$. aureus isolates, associated with four sequence-types (STs): t084/ ST15 ( $n=1) ; \mathrm{t} 10579 / \mathrm{ST} 291(n=3) ; \mathrm{t} 355, \mathrm{t} 4690 / \mathrm{ST} 152$ $(n=2)$; and t6618 /ST6 $(\mathrm{n}=1)$ (Table 1$)$. All the isolates were negative for the clonal complex (CC) 398 specific PCR.

The genes encoding for PVL were detected in 2 out of 7 MSSA isolates (28.6\%), specifically in t355/ST152 and t4690/ST152 isolates from chicken and cow origins, respectively. The eta and tst virulence genes were found in isolates of cow origin: 1) eta gene in one isolate t084/ ST15; and 2) tst gene in three t10579/ST291 isolates. The enterotoxin genes sea and see were present in one isolate of lineage t6618/ST6 recovered of a cow. All the isolates hosted haemolysin encoding genes. In addition, all $S$. aureus isolates lacked the $s c n$ gene (IEC-negative). This data is summarised in Table 1.

Table 1 S. aureus from nasal samples of healthy cows and chicken: phenotypic and genotypic characteristics

\begin{tabular}{|c|c|c|c|c|c|c|c|}
\hline \multirow[b]{2}{*}{ Origin } & \multirow[b]{2}{*}{ Strain } & \multirow[b]{2}{*}{$\mathrm{ST} / \mathrm{CC}$} & \multirow[b]{2}{*}{ Spa-type } & \multicolumn{2}{|c|}{ Antimicrobial resistance } & \multirow[b]{2}{*}{ Virulence genes } & \multirow[b]{2}{*}{$\operatorname{scn}$} \\
\hline & & & & Phenotype $^{a}$ & Genotype & & \\
\hline Cow & C10068 & ST6/CC6 & t6618 & PEN-TET & blaZ, tet $(K)$ & sea, see, hla, hlb, hld & negative \\
\hline Cow & C10067 & ST15/CC15 & t084 & PEN-TET & blaZ, tet $(K)$ & eta, hla, hld & negative \\
\hline Cow & C10064 & ST291 & t10579 & PEN & blaz & tst, hla, hlb, hld, hlg & negative \\
\hline Cow & C10066 & ST291 & t10579 & PEN & blaz & tst, hla, hlb, hld, hlg & negative \\
\hline Cow & C10063 & ST291 & t10579 & PEN & blaz & tst, hla, hlb, hld, hlg & negative \\
\hline Cow & C10065 & ST152/CC152 & t4690 & PEN & blaz & lukF/luks-PV, hla, hlb, hld, hlg & negative \\
\hline Chicken & C10056 & ST152/CC152 & t355 & Susceptible & - & lukF/luks-PV, hla, hlb, hld, hlg & negative \\
\hline
\end{tabular}

${ }^{\mathrm{a}} P E N$ penicillin, TET tetracycline 
Table 2 Non-aureus staphylococcal species in nasal samples of healthy cows and chicken: phenotypic and genotypic characteristics

\begin{tabular}{|c|c|c|c|}
\hline \multirow[b]{2}{*}{ Origin } & \multirow[b]{2}{*}{ Species } & \multicolumn{2}{|c|}{ Antimicrobial Resistance } \\
\hline & & Phenotype $^{a}$ & Genotype \\
\hline $\begin{array}{l}\text { ( } \mathrm{n}^{\circ} \text { of positive } \\
\text { animals) }\end{array}$ & ( $n^{\circ}$ of isolates) & $\begin{array}{l}\text { ( } n^{\circ} \text { of } \\
\text { isolates) }\end{array}$ & ( $n^{\circ}$ of isolates) \\
\hline \multirow[t]{10}{*}{ Cow (35) } & S. sciuri (16) & TET (2) & $\operatorname{tet}(\mathrm{K})(2)$ \\
\hline & & TET (1) & $\operatorname{tet}(\mathrm{K})$ \\
\hline & & Susceptible (13) & - \\
\hline & S. simulans (8) & TET (2) & $\operatorname{tet}(\mathrm{K})(2)$ \\
\hline & & Susceptible (6) & - \\
\hline & S. haemolyticus (3) & SXT (1) & $d f r G$ \\
\hline & & Susceptible (2) & - \\
\hline & S. chromogenes (3) & Susceptible (3) & \\
\hline & S. hyicus (5) & TET (1) & $\operatorname{tet}(\mathrm{K})$ \\
\hline & & Susceptible (4) & - \\
\hline \multirow[t]{4}{*}{ Chicken (5) } & S. simulans (3) & PEN-TET (1) & blaZ, tet $(K)$ \\
\hline & & TET-SXT (2) & $\operatorname{tet}(\mathrm{L})(2), \operatorname{dfr} K(2)$ \\
\hline & S. haemolyticus (1) & TET-SXT & $\operatorname{tet}(\mathrm{K}), \operatorname{tet}(\mathrm{L}), \mathrm{dfr} \mathrm{K}$ \\
\hline & S. hominis (1) & ERY-TET & $\operatorname{tet}(\mathrm{L}), m s r(\mathrm{~A}) / m s r(\mathrm{~B})$ \\
\hline
\end{tabular}

${ }^{a} P E N$ penicillin, TET tetracycline, ERY erythromycin,

SXT trimethoprim/sulfamethoxazole

\section{Non-aureus staphylococci: antimicrobial resistance phenotype and genotype}

Among the 40 non-S. aureus isolates, $32.5 \%$ showed resistance to at least one antimicrobial agent tested. The following resistance rates and genotypes were observed: tetracycline $[27.5 \%$; tet $(\mathrm{K}), \operatorname{tet}(\mathrm{L})]$, trimethoprim/sulfamethoxazole (SXT) (10\%; dfrG, dfrK), penicillin (2.5\%; blaZ), erythromycin $[2.5 \% ; m s r(\mathrm{~A}) / m s r(\mathrm{~B})]$ and clindamycin $(2.5 \%)$. It should be noted that resistance to tetracycline was mediated only by tet $(\mathrm{K})$ gene for the isolates from cow origin, and by either tet $(\mathrm{K})$ or tet $(\mathrm{L})$ for the isolates recovered from chicken; furthermore, $d f r G$ was present in one isolate from cow, whereas $d f r K$ was detected in isolates of chicken origin.

\section{Discussion}

Farm animals are a source for staphylococcal species as well as for their resistance genes and virulence factors [28]. The transmission to humans could occur either through direct contact or via animal derived food [1], hence the importance of analysing staphylococci from food-producing animals.

In this study, the frequency of detection of S. aureus was low in cows (4\%) and chickens (0.5\%). A similar study from Nigeria showed a rate of $2.6 \%$ in cattle from slaughterhouses [29]. A higher detection rate was observed in other animals intended for human consumption, such as pigs in Senegal (12.3\%) [13] as well as goat and sheep, according to studies carried out in Tunisia $[28,30]$.

Among the $S$. aureus detected in our work, the most frequently detected lineage was ST291, followed by ST152; however, a similar study performed in Senegal on isolates of pigs and pig farmers showed a predominance of the lineages ST15 and ST152, containing the PVL genes [13]. The sequence type ST291 is a ST398 double locus variant, which encodes two specific subunits, sauI-hsdS1 and sauI$h s d S 2$, located in GI $\alpha$ and GI $\beta$ genomic islands respectively, whereas CC398 isolates encode a single sauI-hsdS1, located in GI $\alpha$ [31]. Furthermore, sauI-hsdS1 of ST291 showed $60 \%$ nucleotide similarity to the CC398 sauI-hsdS1; consequently, the CC398 specific PCR cannot identify ST291 isolates as part of the CC398 cluster [25, 31], as was the case in our study. The lineage ST291 has been previously described as the major lineage in cattle with mastitis in Egypt [32]; they were all MSSA harbouring scn and PVL genes, unlike our isolates. The lineage ST15, mainly associated to MSSA isolates, frequently harbours PVL and enterotoxins [5] and is highly prevalent in African countries, according to the findings of healthcare institutions [33, 34]. Nevertheless, this lineage has also been found in animals (cattle, poultry and donkeys) $[3,8,30]$. The clonal complex CC152 was reported as one of the major clonal complexes in many African countries (healthcare environment) (Madagascar, Morocco, Cameroon, Gabon, Niger, Nigeria, Ghana, Mali and Senegal) [13, 33]. The lineage ST152 is sporadically associated to community-associated (CA) MRSA in some European countries, whereas ST152-MSSA is a particularly frequent clone in Western and Central Africa [33, 35]. PVL is the most important toxin secreted by $S$. aureus and is involved in severe skin infections and life-threatening diseases. This toxin is found all over the world, mainly among CA S. aureus isolates $[6,35]$. Nonetheless, it was also described in isolates from farm/wild animals (linked to the lineages ST5, ST8, ST15, ST80, ST152, and ST121) [36-38] and animal-derived food (linked to the lineages ST8, ST121, and ST152) [3, 39]. PVL is very frequently harboured by MSSA isolates in Africa, where PVL-positive $S$. aureus is considered endemic [5]. In this work, all the PVLpositive isolates were MSSA (28.6\% of $S$. aureus detected), contrary to the results obtained from healthy sheep in Tunisia, showing only PVL-positive MRSA (6.8\% of S. aureus detected) [40]. In a previous study performed on pigs in Senegal, $38.4 \%$ of the $S$. aureus isolates harboured the PVL toxin, being $78.6 \%$ of them MSSA [13]. Contrarily to the above mentioned studies highlighting the recurrence of PVL-positive $S$. aureus among animals intended for human consumption in Africa, the absence of PVL was noted among $S$. aureus recovered from donkeys for meat consumption in Tunisia [30]. Furthermore, other virulence encoding genes were detected among the isolates (sea, see, eta, $t s t$, hla, hlb, hld and $h l g)$. The presence of staphylococcal 
enterotoxins (SEs) in bovine isolates is worrisome since, as the literature shows, SEs are detected more often in cows with mastitis than in healthy cows [41]. Furthermore, SEA is the enterotoxin most frequently reported in food (encoded by sea gene) and the main cause of staphylococcal food poisoning (SFP) in many countries [42]; it is generally detected in meat, poultry and milk, among others. Nevertheless, SEE (encoded by see gene) is rarely reported in food and foodproducing animals, although it was involved in some cases of SFP outbreaks in France [42]. Interestingly, none of our isolates carried the genes which encode the toxins SEC or SED, described as the most recurrent in bovines [43]. The presence of such virulent factors in $S$. aureus from foodproducing animals, especially in African countries like Senegal, is a big concern for public health to the extent that in some cases, the animals are raised in the houses or sold in open markets, where they are in contact with people and retail food products. This easily results in the dissemination of staphylococcal virulence genes in different niches of the community. The lack of scn gene in our isolates suggests their being of animal origin, as expected, thus discarding a potential human origin (by handlers during slaughter).

In addition, other species were detected, the most prevalent being S. sciuri and S. simulans, followed by $S$. hyicus, S. haemolyticus, S. chromogenes and S. hominis. The coagulase-negative species mentioned above seem to be frequent in cattle and poultry samples [36, 44, 45]. Increasingly considered as opportunistic pathogens for humans and animals [44], coagulase-negative staphylococci are thought to be a reservoir for important resistance genes that could be transferred to $S$. aureus isolates [45], hence the importance of their surveillance.

Regarding the antimicrobial resistance, the phenotypes and genotypes observed in this study are frequent among $S$. aureus isolates from food-producing animals and animal-derived food [12, 28, 36, 38]. Similar phenotypes were previously observed among pig isolates of the same country [13]. Resistance to at least one antimicrobial agent was evidenced in $32.5 \%$ of the non-S. aureus isolates tested (tetracycline, SXT, penicillin, erythromycin and clindamycin), maybe due to the very frequent use of beta-lactams, tetracyclines, lincosamides and sulphonamides in the veterinary sector (food-producing animals and pets) [46].

\section{Conclusion}

A relatively low prevalence of $S$. aureus has been observed in nasal samples of food-producing animals (chickens and cows) in Senegal, with S. aureus being MSSA in all cases. Nevertheless, all the $S$. aureus isolates detected harboured at least one virulence gene (especially PVL and enterotoxins genes), which could be a concern for food-safety and public health, particularly in a developing country with areas in which access to medical care is difficult and limited.

\section{Methods \\ Sample collection}

From May to July 2017, nasal samples of 149 cows and 199 chickens (348 animals) were taken with aseptic swabs in the General Society of Slaughterhouses of Senegal (SOGAS) and a local market, respectively. In all cases, nasal samples were obtained from dead animals, just after they were sacrificed to human consumption as part of routine work in the slaughterhouse and the market.

\section{Isolation and identification of staphylococci strains}

Tubes of $5 \mathrm{ml}$ of Brain Heart Infusion (BHI) broth $(+\mathrm{NaCl} 6.5 \%)$ were inoculated with the nasal swabs and then incubated at $37^{\circ} \mathrm{C}$ for $24 \mathrm{~h}$. After growth, bacterial culture was distributed on plates of mannitol-salt-agar (Conda, Madrid/Spain), Baird Parker (Becton Dickinson, Heidelberg/Germany) and oxacillin-resistance-screeningagar-base (Oxoid, Hampshire/England) for S. aureus and MRSA recovery. Non-aureus staphylococci were also identified and characterised. Up to two colonies/plate with staphylococcal morphology were isolated and subjected to Dnase agar test (Conda, Madrid/Spain) and identification by matrix-assisted laser desorption/ ionization time of flight (MALDI-TOF) mass spectrometry (Bruker, Massachusetts/USA).

\section{Antibiotic susceptibility and resistance genes detection} For all staphylococci identified, susceptibility to penicillin (10 units), cefoxitin $(30 \mu \mathrm{g})$, gentamicin $(10 \mu \mathrm{g})$, tobramycin $(10 \mu \mathrm{g})$, tetracycline $(30 \mu \mathrm{g})$, chloramphenicol $(30 \mu \mathrm{g})$, erythromycin $(15 \mu \mathrm{g})$, clindamycin $(2 \mu \mathrm{g})$, ciprofloxacin $(5 \mu \mathrm{g})$, linezolid $(30)$ and SXT $(1.25+23.75 \mu \mathrm{g})$ was analysed by disk-diffusion method [18]. In addition, susceptibility to streptomycin $(30 \mu \mathrm{g})$ was also tested [19]. Antimicrobial resistance genes were determined by PCR, according to the resistance phenotype of the isolates: penicillin (blaZ), tetracycline $[\operatorname{tet}(\mathrm{K}), \operatorname{tet}(\mathrm{L})$, and tet $(\mathrm{M})]$, macrolides $[\operatorname{erm}(\mathrm{A})$, $\operatorname{erm}(\mathrm{B}), \operatorname{erm}(\mathrm{C}), \operatorname{msr}(\mathrm{A}) / m s r(\mathrm{~B})]$, and trimethoprim (dfrA, $d f r D, d f r G, d f r K)$ [20-23] .

\section{Molecular typing and virulence genes study in S. aureus isolates}

Spa-typing and Multilocus sequence typing (MLST) were performed for $S$. aureus strains by polymerase chain reaction (PCR) and sequencing and the spa-type, sequence type (ST), and clonal complex (CC) were determined as previously described [24]. In addition, a specific PCR was performed for the livestock-associated CC398 lineage detection [25]. The presence of the genes encoding the PVL (lukF/lukS-PV), exfoliative toxins (eta 
and $e t b$ ), toxic shock syndrome toxin (tst), haemolysins (hla, hlb, hld, hlg and hlgv) and SEs (sea, seb, sec, sed, see, seg, seh, sei, sej, sek, sel, sem, sen, seo, sep, seq, ser, and seu) was screened by PCR [14, 26, 27]. The gene scn, was also tested for $S$. aureus isolates [14]. Positive and negative control strains of the University of La Rioja were included in all PCR reactions.

\section{Abbreviations}

BHI: Brain Heart Infusion; CA: Community-Associated; CC: Clonal Complex; IEC: Immune Evasion Cluster; MALDI-TOF: Matrix-Assisted Laser Desorption/ Ionization Time Of Flight; MLST: Multilocus Sequence Typing; MRSA: Methicillin-Resistant S. aureus; MSSA: Methicillin-Susceptible S. aureus: PCR: Polymerase Chain Reaction; PVL: Panton-Valentine Leucocidin; SEs : Staphylococcal Enterotoxins; SFP: Staphylococcal Food Poisonning; SSTIs: Skin and Soft Tissues Infections; ST: Sequence Type; SXT: Trimethoprim/ Sulfamethoxazole; TSST: Toxic Shock Syndrome Toxin

\section{Acknowledgments}

We acknowledge the foundation "Mujeres por África" and the "Universidad de La Rioja" (Spain) for OMM predoctoral fellowship, the "Universidad de La Rioja" (Spain) for LRR's predoctoral FPI fellowship, the "Laboratoire d'Analyses et d'Essais" of the "Ecole Supérieure Polytechnique" (Dakar, Senegal), and the "Société Générale des abattoirs du Sénégal".

\section{Authors' contributions}

CT conceived and designed the study. MD, CGMD and BH designed and participate in the sampling procedure. OMM, LRR and MD performed laboratory works. OMM and CT interpreted the results and do the first writing of manuscript. All authors have revised and approved the manuscript.

\section{Funding}

This work was supported by project SAF2016-76571-R from the Agencia Estatal de Investigación (AEI) of Spain and Fondo Europeo de Desarrollo Regional (FEDER) of EU. The AEI and FEDER of EU are public organizations that finance research projects but the design of the study, collection, analysis and interpretation and writing of papers is under the complete responsibility of the researchers that carried out the study.

\section{Availability of data and materials}

The datasets used and/or analysed during the current study are available from the corresponding author on reasonable request.

\section{Ethics approval and consent to participate}

In this study nasal samples were taken from animals during routine processing at the slaughterhouse and the market, once they were dead. No animal was sampled alive or sacrificed for the purpose of this study. Thus, according to the Spanish National law for the protection of animals (RD53/ 2013) that transcribes the EU directive 2010/63/UE, no ethics committee approval was deemed necessary. Furthermore, ethic committee approval was not deemed necessary based on the Article 7.1 (on the recommendations for animal welfare) and the Article 7.8 (on the use of animals in research and education) of the OIE Terrestrial Animal Health Code followed by Senegal.

At the time of processing the entity responsible for the animals was the slaughterhouse and authorization for sample collection was obtained from the directing board of the slaughterhouse. Also, the chicken sampling was authorized verbally by the owner which is responsible for the animals.

\section{Consent for publication}

Not Applicable.

\section{Competing interests}

The authors declare that they have no competing interests.

\section{Author details}

'Departamento Agricultura y Alimentación, Área de Bioquímica y Biología Molecular, Universidad de La Rioja, Madre de Dios 51, 26006 Logroño, Spain.
${ }^{2}$ LAE/ Ecole Supérieure polytechnique de Dakar, UCAD, Dakar, Sénégal. ${ }^{3}$ Service Vétérinaire, Société de gestion des abattoirs du Sénégal, Dakar, Sénégal.

Received: 28 June 2019 Accepted: 10 October 2019

Published online: 04 November 2019

\section{References}

1. Kluytmans JAJW. Methicillin-resistant Staphylococcus aureus in food products: cause for concern or case for complacency? Clin Microbiol Infect. 2010;16:11-5. https://doi.org/10.1111/j.1469-0691.2009.03110.x.

2. Lozano C, López M, Gómez-Sanz E, Ruiz-Larrea F, Torres C, Zarazaga M. Detection of methicillin-resistant Staphylococcus aureus ST398 in food samples of animal origin in Spain. J Antimicrob Chemother. 2009;64:1325-46.

3. Jans C, Merz A, Johler S, Younan M, Tanner SA, Kaindi DWM, et al. East and west African milk products are reservoirs for human and livestockassociated Staphylococcus aureus. Food Microbiol. 2017;65:64-73. https://doi.org/10.1016/j.fm.2017.01.017.

4. Lina G, Pie Y, Godail-gamot F, Bes M, Peter M-O, Gauduchon V, et al. Involvement of Panton-valentine Leukocidin - producing Staphylococcus aureus in primary skin infections and pneumonia. Clin Infect Dis. 1999;29:1128-32.

5. Schaumburg F, Alabi AS, Peters G, Becker K. New epidemiology of Staphylococcus aureus infection in Africa. Clin Microbiol Infect. 2014;20:58996. https://doi.org/10.1111/1469-0691.12690

6. Vindel A, Trincado P, Cuevas O, Ballesteros C, Bouza E, Cercenado E. Molecular epidemiology of community-associated methicillin-resistant Staphylococcus aureus in Spain: 2004-12. J Antimicrob Chemother. 2014;69:2913-9.

7. Nowakiewicz A, Ziółkowska G, Zieba P, Gnat S, Wojtanowicz-Markiewicz K, Trościańczyk A. Coagulase-positive Staphylococcus isolated from wildlife: identification, molecular characterization and evaluation of resistance profiles with focus on a methicillin-resistant strain. Comp Immunol Microbiol Infect Dis. 2016:44:21-8.

8. Lozano C, Gharsa H, Ben Slama K, Zarazaga M, Torres C. Staphylococcus aureus in animals and food: methicillin resistance, prevalence and population structure. A review in the african continent. Microorganisms. 2016:4:12.

9. van Wamel WJB, SHM R, van Kessel KPM, van Strijp JA, Ruyken M. The innate immune modulators staphylococcal complement inhibitor and chemotaxis inhibitory protein of Staphylococcus aureus are located on $\beta$ Hemolysin-converting bacteriophages. J Bacteriol. 2006;188:1310-5.

10. Bendarif E, Khalil A, Rayes A, Bennour E, Dhawi A, Lowe JJ, et al. Characterization of methicillin-resistant Staphylococcus aureus isolated at Tripoli Medical Center , Libya, between 2008 and 2014. J Med Microbiol. 2019;65:1472-5.

11. De Boeck H, Vandendriessche S, Hallin M, Batoko B, Alworonga J, Mapendo $B$, et al. Staphylococcus aureus nasal carriage among healthcare workers in Kisangani, the Democratic Republic of the Congo. Eur J Clin Microbiol Infect Dis. 2015;34:1567-72.

12. Mekonnen SA, Lam TJGM, Hoekstra J, Rutten VPMG, Tessema TS, Broens EM, et al. Characterization of Staphylococcus aureus isolated from milk samples of dairy cows in small holder farms of North-Western Ethiopia. BMC Vet Res. 2018;14:246

13. Fall C, Seck A, Richard V, Ndour M, Sembene M, Laurent F, et al. Epidemiology of Staphylococcus aureus in pigs and farmers in the largest farm in Dakar. Senegal Foodborne Pathog Dis. 2012;9:962-5.

14. Benito D, Gómez P, Lozano C, Estepa V, Gómez-Sanz E, Zarazaga M, et al. Genetic lineages, antimicrobial resistance, and virulence in Staphylococcus aureus of meat samples in Spain: analysis of immune evasion cluster (IEC) genes. Foodborne Pathog Dis. 2014;11:354-6.

15. Benito D, Lozano C, Rezusta A, Ferrer I, Vasquez MA, Ceballos S, et al. Characterization of tetracycline and methicillin resistant Staphylococcus aureus strains in a Spanish hospital: is livestock-contact a risk factor in infections caused by MRSA CC398? Int J Med Microbiol. 2014;304:1226-32. https://doi.org/10.1016/j.jimm.2014.09.004

16. Mama OM, Ruiz-Ripa L, Fernández-Fernández R, González-Barrio D, RuizFons JF, Torres C. High frequency of coagulase-positive staphylococci carriage in healthy wild boar with detection of MRSA of lineage ST398- 
t011. FEMS Microbiol Lett. 2019;366:fny292. doi:https://doi.org/10.1093/ femsle/fny292.

17. Gómez P, Lozano C, Benito D, Estepa V, Tenorio C, Zarazaga M, et al. Characterization of staphylococci in urban wastewater treatment plants in Spain, with detection of methicillin resistant Staphylococcus aureus ST398. Environ Pollut. 2016;212:71-6.

18. CLSI, 2018. Performance standards for antimicrobial susceptibility testing: $28^{\text {th }}$ ed. CLSI supplement M100, clinical laboratory standards institute, Wayne, PA 2018.

19. CASFM. Comité de l'Antibiogramme de la Société Française de Microbiologie. Recommandations vétérinaires. 2018; https:/www.sfmmicrobiologie.org/

20. Sutcliffe J, Grebe T, Tait-Kamradt A, Wondrack L. Detection of erythromycinresistant determinants by PCR. Antimicrob Agents Chemother. 1996;40:2562-6.

21. Schnellmann C, Gerber V, Rossano A, Jaquier V, Panchaud Y, Doherr MG et al. Presence of new mecA and $m p h(C)$ variants conferring antibiotic resistance in Staphylococcus spp. isolated from the skin of horses before and after clinic admission. J Clin Microbiol. 2006;44:4444-54.

22. Aarestrup FM, Agerso Y, Gerner-Smidt P, Madsen M, Jensen LB. Comparison of antimicrobial resistance phenotypes and resistance genes in Enterococcus faecalis and Enterococcus faecium from humans in the community, broilers, and pigs in Denmark. Diagn Microbiol Infect Dis. 2000;37:127-37.

23. Gómez-Sanz E, Torres C, Lozano C, Fernández-Pérez R, Aspiroz C, Ruiz-Larrea F, et al. Detection, molecular characterization, and clonal diversity of methicillinresistant Staphylococcus aureus CC398 and CC97 in spanish slaughter pigs of different age groups. Foodborne Pathog Dis. 2010;7:1269-77.

24. Lozano C, Rezusta A, Gómez P, Gómez-sanz E, Báez N, Martin-Saco G, et al. High prevalence of spa types associated with the clonal lineage CC398 among tetracycline-resistant methicillin-resistant Staphylococcus aureus strains in a Spanish hospital. J Antimicrob Chemother. 2012;67:330-4.

25. Stegger M, Lindsay JA, Moodley A, Skov R, Broens EM, Guardabassi L. Rapid PCR detection of Staphylococcus aureus clonal complex 398 by targeting the restrictionmodification system carnying sau1-hsdS1. J Clin Microbiol. 2011;49:732-4.

26. Hwang SY, Kim SH, Jang E, Kwon NH, Park YK, Koo HC, et al. Novel multiplex PCR for the detection of the Staphylococcus aureus superantigen and its application to raw meat isolates in Korea. Int J Food Microbiol. 2007;117:99-105.

27. Jarraud S, Mougel C, Thioulouse J, Lina G, Meugnier H, Forey F, et al. Relationships between Staphylococcus aureus genetic background, virulence factors, agr groups (alleles), and human disease. Infect Immun. 2002;70:631-41.

28. Ben Said M, Abbassi MS, Gómez P, Ruiz-Ripa L, Sghaier S, El Fekih O, et al. Genetic characterization of Staphylococcus aureus isolated from nasal samples of healthy ewes in Tunisia. High prevalence of CC130 and CC522 lineages. Comp Immunol Microbiol Infect Dis. 2017;51:37-40. https://doi. org/10.1016/j.cimid.2017.03.002

29. Odetokun IA, Ballhausen B, Adetunji VO, Ghali-mohammed I, Adelowo MT, Adetunji SA, et al. Staphylococcus aureus in two municipal abattoirs in Nigeria : risk perception, spread and public health implications. Vet Microbiol. 2018;216:52-9. https://doi.org/10.1016/j.vetmic.2018.01.022.

30. Gharsa H, Ben Sallem R, Ben Slama K, Gómez-Sanz E, Lozano C, Jouini A, et al. High diversity of genetic lineages and virulence genes in nasal Staphylococcus aureus isolates from donkeys destined to food consumption in Tunisia with predominance of the ruminant associated CC133 lineage. BMC Vet Res. 2012;8:203. https://doi.org/10.1186/1746-6148-8-203.

31. Stegger M, Aziz M, Chroboczek T, Price LB, Ronco T, Kiil K, et al. Genome analysis of Staphylococcus aureus ST291, a double locus variant of ST398, reveals a distinct genetic lineage. PLoS One. 2013;8:e63008.

32. El-ashker M, Gwida M, Hebert T, Stefan M, Ehricht R, El-Gohary F, et al. staphylococci in cattle and buffaloes with mastitis in Dakahlia Governorate, Egypt. J Dairy Sci. 2015;98:7450-9.

33. Breurec $S$, Fall $C$, Pouillot $R$, Boisier $P$, Brisse $S$, Diene-Sarr $F$, et al. Epidemiology of methicillin-susceptible Staphylococcus aureus lineages in five major African towns : high prevalence of Panton - valentine leukocidin genes. Clin Microbiol Infect. 2010;17:633-9. https://doi.org/10.1111/j.14690691.2010.03320.x.

34. Eibach D, Nagel M, Hogan B, Azuure C, Krumkamp R, Dekker D, et al. Nasal carriage of Staphylococcus aureus among children in the Ashanti region of Ghana. PLoS One. 2017:12:e0170320.

35. Abdulgader SM, Shittu AO, Nicol MP, Kaba M. Molecular epidemiology of methicillin-resistant Staphylococcus aureus in Africa : a systematic review. Front Microbiol. 2015;6:348.
36. Mama OM, Gómez-Sanz E, Ruiz-Ripa L, Gómez P, Torres C. Diversity of staphylococcal species in food producing animals in Spain, with detection of PVL-positive MRSA ST8 (USA300). Vet Microbiol. 2019;233:5-10. https:// doi.org/10.1016/j.vetmic.2019.04.013.

37. Agabou A, Ouchenane Z, Essebe CN, Khemissi S, Tedj M, Chehboub E, et al. Emergence of nasal carriage of ST80 and ST152 PVL+ Staphylococcus aureus isolates from livestock in Algeria. Toxins (Basel). 2017;9:E303.

38. Nworie A, Onyema AS, Okekpa SI, Elom MO, Umoh NO, Usanga VU, et al. A novel methicillin-resistant Staphylococcus aureus t1 1469 and a poultry endemic strain t002 ( ST5 ) are present in chicken in Ebonyi State, Nigeria. Biomed Res Int. 2017;2017:2936461. https://doi.org/10.1155/2017/2936461.

39. Kraushaar B, Fetsch A. First description of PVL-positive methicillin-resistant Staphylococcus aureus (MRSA) in wild boar meat. Int J Food Microbiol. 2014; 186:68-73. https://doi.org/10.1016/j.jffoodmicro.2014.06.018.

40. Gharsa H, Ben Slama K, Lozano C, Gómez-Sanz E, Klibi N, Ben Sallem R, et al. Prevalence, antibiotic resistance, virulence traits and genetic lineages of Staphylococcus aureus in healthy sheep in Tunisia. Vet Microbiol. 2012;156:367-73.

41. Monistero V, Graber HU, Pollera C, Cremonesi P, Castiglioni B, Bottini E, et al. Staphylococcus aureus isolates from bovine mastitis in eight countries: Genotypes, detection of genes encoding different toxins and other virulence genes. Toxins (Basel). Toxins 2018;10(6):E247. https:/doi.org/10.3390/toxins10060247.

42. Argudín MÁ, Mendoza MC, Rodicio MR. Food poisoning and Staphylococcus aureus enterotoxins. Toxins (Basel). 2010;2:1751-73. https://doi.org/10.3390/ toxins2071751.

43. Cardoso HFT, Silva N, Sena MJ, Carmo LS. Production of enterotoxins and toxic shock syndrome toxin by Staphylococcus aureus isolated from bovine mastitis in Brazil. Lett Appl Microbiol. 1999;29:347-9.

44. Boamah VE, Agyare C, Odoi H, Adu F, Gbedema SY, Dalsgaard A. Prevalence and antibiotic resistance of coagulase-negative staphylococci isolated from poultry farms in three regions of Ghana. Infect Drug Resist. 2017;10:175-83.

45. Becker K, Heilmann C, Peters G. Coagulase-negative staphylococci. Clin Microbiol Rev. 2014:27:870-926

46. Prestinaci F, Pezzotti P, Pantosti A. Antimicrobial resistance: a global multifaceted phenomenon. Pathog Glob Health. 2015;109:309-18. https:// doi.org/10.1179/2047773215Y.0000000030

\section{Publisher's Note}

Springer Nature remains neutral with regard to jurisdictional claims in published maps and institutional affiliations.
Ready to submit your research? Choose BMC and benefit from:

- fast, convenient online submission

- thorough peer review by experienced researchers in your field

- rapid publication on acceptance

- support for research data, including large and complex data types

- gold Open Access which fosters wider collaboration and increased citations

- maximum visibility for your research: over $100 \mathrm{M}$ website views per year

At $\mathrm{BMC}$, research is always in progress.

Learn more biomedcentral.com/submissions 